\title{
Obtención y caracterización de un anticuerpo específico contra la hormona luteinizante humana
}

\author{
Adriana Umaña, Cecilia Anzola, Myriam Sánchez-Gómez
}

\begin{abstract}
Resumen
En el presente trabajo se describe la obtención del anticuerpo policlonal específico contra la hormona luteinizante humana (HL). La hormona fue purificada a partir de una fracción rica en glicoproteínas, obtenida de hipófisis humanas, siguiendo el método desarrollado previamente en el proyecto basado en diferencias de solubilidad y constante dieléctrica entre las diferentes proteínas. El antisuero específico se obtuvo por inoculación del antígeno en conejos raza Nueva Zelanda y su producción controlada valorando el título por RIA. La caracterización parcial del antisuero se realizó mediante la determinación del título óptimo, afinidad, especificidad y su aplicabilidad para la cuantificación en términos de curva estándar y control de calidad, en comparación con un antisuero de referencia internacional. Los resultados indicaron que el anticuerpo obtenido puede emplearse en la cuantificación de HL por RIA.
\end{abstract}

\begin{abstract}
Summary
The present work describes the production of a specific polyclonal human luteinising hormone (LH) antibody. The hormone was purified from a glycoprotein-rich section obtained from human hypophyses, using a previously standarised laboratory method based on differences in solubility and dielectric constant among the different proteins. The specific antiserum was generated in New Zealand rabbits and the titre was assessed by RIA. Partial characterisation of antisera was performed by determining optimum titre, affinity, specificity and its quantitative capability, as assessed in comparison with an international reference antiserum. Results showed that the antiserum obtained is suitable for the quantitation of LH by RIA.
\end{abstract}

La hormona luteinizante $(\mathrm{HL})$ es una glicoproteína de $28.000 \mathrm{Da}$ (204 aa), segregada por la adenohipófisis y constituida por dos subunidades $(\alpha$ y $\beta$ ), entrelazadas por enlaces disulfuro. La subunidad $\alpha$ es idéntica en todas las hormonas glicoproteicas ( $\mathrm{LH}$, hormona folículo estimulante (FSH), hormona estimulante de la tiroides (TSH) y la gonadotropina coriónica (CG); la subunidad $\beta$ muestra gran homología entre ellas y es la encargada de conferir especificidad a la molécula (1). Su regulación es controlada por la hormona liberadora de gonadotropinas (GnRH o LHRH) (2), producida en el hipotálamo y, a su vez, modulada por adrenérgicos y péptidos gonadales (3).

Las gonadotropinas ( $\mathrm{LH}$ y FSH) cumplen su función en la ovulación, la espermatogénesis y la biosíntesis de esteroides sexuales. En el hombre, su concentración en el plasma se mantiene relativamente constante $(5-25 \mathrm{mUl} / \mathrm{mL})$ 
mientras que, en la mujer, varía de acuerdo con la fase del ciclo menstrual $(4-158 \mathrm{mUI} / \mathrm{mL})$.

La valoración del contenido de $\mathrm{LH}$ tiene interés particular en los estudios de fertilidad y de los desórdenes endocrinos tanto en la mujer como en el hombre (4). Se realiza por diversas técnicas, siendo la más utilizada el radioinmunoanálisis (RIA) ya que permite la dosificación de picogramos de masa/L, valores en los que se encuentra la hormona en la sangre; además, esta técnica se caracteriza por su sensibilidad, precisión, especificidad y facilidad de ejecución (5).

El objetivo de este trabajo fue el de obtener un anti-LH policional para ser utilizado en ei RIA, contribuyendo a la implementación de una tecnología propia para la obtención de kits a nivel nacional con fines de diagnóstico y con las consecuentes ventajas económicas.

\section{Materiales y métodos}

\section{Extracción y purificación de LH}

El residuo proveniente de la extracción de la hormona del crecimiento y de prolactina de un macerado de glándulas hipofisiarias humanas recolectadas ( 6 horas postmortem) en el Departamento de Patología del Instituto de Medicina Legal de Santa Fe de Bogotá, se trató con acetato de amonio $\left(\mathrm{AcONH}_{4}\right), 4 \mathrm{mM}, \mathrm{pH} 5,3$; se realizaron tres extracciones $G_{1}, G_{2}$ y $G_{3}$ (figura 1) y se centrifugó a $10.000 \mathrm{rpm}$ durante 30 minutos, con el fin de extraer las hormonas glicoproteicas.

La fracción liofilizada redisuelta en solución amortiguada de fosfato $10 \mathrm{mM}$, pH 7,4, se pasó a través de una columna de DEAE-celulosa $(1,6$ $\times 90 \mathrm{~cm}$ ) previamente equilibrada con la misma solución amortiguadora, eluyendo a una velocidad de $9 \mathrm{~mL} / \mathrm{h}$, y detectando la presencia de proteína por lecturas de absorbancia a 280 $\mathrm{nm}$. La proteína retenida se eluyó aplicando un gradiente continuo de fuerza iónica en solución amortiguada de fosfato $10 \mathrm{mM}, \mathrm{pH} 7,4(0-1 \mathrm{M}$ $\mathrm{NaCl})$. El seguimiento de la elución se llevó a cabo mediante lecturas de conductividad ( $\mathrm{mS}$ ) y absorbancia a $280 \mathrm{~nm}$, evaluando el contenido proteico por el método de Lowry (6) y la actividad

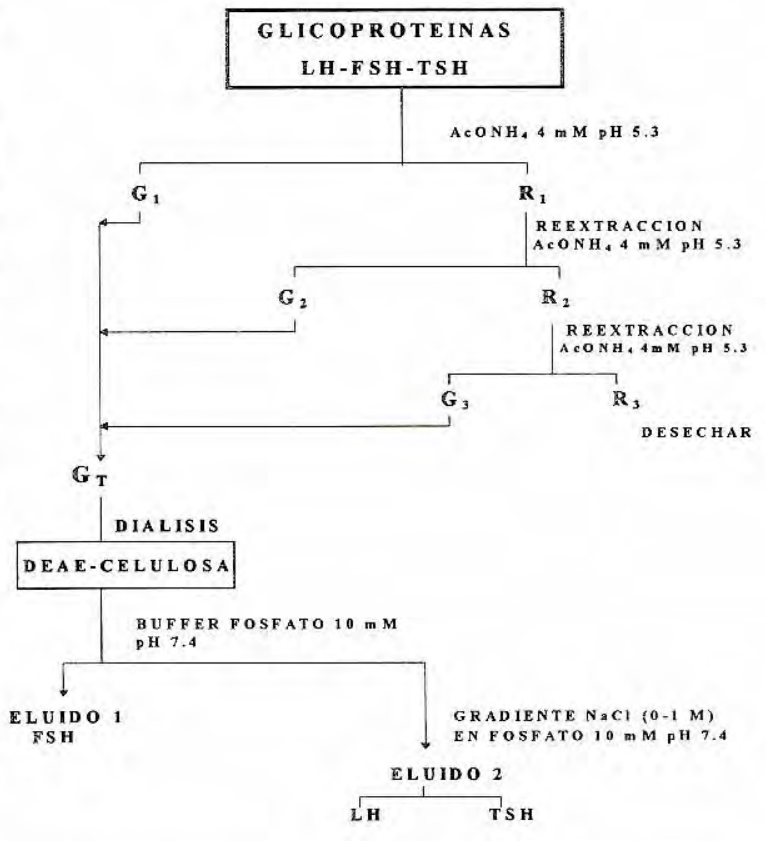

LH: Hormona Lutenizante, FSH: Hormona Foliculo-Estimulante; TSH: Hormona Estimulante de la Tiroides; $\mathrm{G}_{1}, \mathrm{G}_{2}, \mathrm{G}_{3}$, $\mathrm{G}_{\mathrm{T}}$ : Extractos; $\mathrm{R}_{1}, \mathrm{R}_{2}, \mathrm{R}_{3}$ : Residuos.

Figura 1. Obtención de LH a partir de la fracción glicoproteica procedente de hipófisis humana

hormonal mediante el RIA (5). Las fracciones de interés fueron reunidas, ultrafiltradas (Sartorius, membrana $10 \mathrm{kDa}, 30 \mathrm{lb} / \mathrm{pulg}^{2}$ ) y almacenadas a $-72^{\circ} \mathrm{C}$, hasta su posterior utilización.

\section{Inmunización en conejos}

Partiendo de la fracción purificada de $\mathrm{LH}$, se preparó la solución antigénica $(205 \mu \mathrm{g} / \mathrm{mL}$ de hormona disueita en solución amortiguada de fosfato $50 \mathrm{mM}, \mathrm{pH} 7,4$, emulsificada con un volumen igual de adyuvante completo de Freund) a utilizar como dosis inicial de inmunización. Se inocularon tres conejos, por vía subcutánea, aplicando tres refuerzos (a los 43,63 y 83 días), el primero con igual cantidad inicial de hormona y los otros dos con $100 \mu \mathrm{g}$, todos con adyuvante incompleto de Freund. Se realizaron sangrados después de 10 días de cada inoculación. evaluando el contenido de LH mediante RIA. El sangrado final se realizó por punción cardíaca una vez alcanzado el título constante. Los sueros obtenidos se almacenaron a $-72^{\circ} \mathrm{C}$ y, posteriormente, se liofilizaron. 


\section{Caracterización parcial del anticuerpo}

El comportamiento del antisuero en el RIA se evaluó en diferentes diluciones, escogiéndose como óptima la que presentara un porcentaje de enlace máximo entre 20 y $50 \%$ (7). Mediante las técnicas de inmunodifusión (8), inmunoelectroforesis (9) y reacción cruzada con FSH, se evaluó la especificidad del antisuero. La afinidad del anticuerpo con $\mathrm{LH}$ se determinó mediante la gráfica de Scatchard (10), teniendo en cuenta la curva dosis-respuesta en cada una de ellas.

\section{Aplicabilidad del anti-hLH en RIA}

En la marcación de $\mathrm{LH}$, se empleó un estándar hormonal hLH-I-3 (AFP-8270B) del National Institute of Diabetes, Digestive and Kidney Diseases (NIADDK) cuya potencia para RIA es de 10.000 $\mathrm{UI} / \mathrm{mg}$, y Na${ }^{125}$ Amershan Code IMS 30. La yodinación se realizó por el método de la cloramina $T$ (11) y su purificación por cromatografía de filtración en gel (Sephadex G50) en columna $(1,1 \times 22 \mathrm{~cm})$ equilibrada con

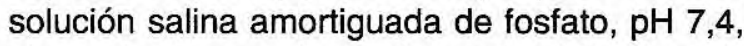
eluyendo a una velocidad de $8,5 \mathrm{~mL} / \mathrm{h}$. El perfil de elución se evaluó por lecturas de radioactividad (contador gamma 1470 Wizard). La actividad específica se calculó mediante la sumatoria de pico y curva de desplazamiento del trazador al 50\% (12).

La curva estándar se realizó siguiendo la metodología de RIA para LH estandarizada en el laboratorio (13), que se basa en la utilización de dos antígenos, uno de los cuales es marcado con un radioisótopo $\left({ }^{125}\right)$ compitiendo ambos por un anticuerpo específico (Ac). El equilibrio existente entre el antígeno marcado-anticuerpo es desplazado al adicionar cantidades progresivas de $\mathrm{LH}$ no marcado $(\mathrm{Ag})$, debido a la formación de dos especies químicas Ag-Ac y $\mathrm{Ag}^{*}$-Ac. Una vez formadas, se incuba con un segundo antisuero (anti-IgG obtenido en el Laboratorio de Hormonas del Departamento de Química de la Universidad Nacional de Colombia mediante inoculación de $\operatorname{lgG}$ de conejo en cabro), se cuantifica midiendo la radiactividad incorporada en dicho proceso.
La confiabilidad del RIA se estableció a través del control de calidad intra-análisis, donde se evaluó la curva dosis-respuesta mediante la utilización del logit-log y la validación estadística con las pruebas Syx y F; la relación respuestaerror y el perfil de imprecisión. También, se analizó el control de calidad inter-análisis construyendo cartas de control de calidad para visualizar la estabilidad del análisis.

\section{Validación del método analítico}

Los parámetros evaluados fueron:

a. Sensibilidad, mediante la determinación de la concentración mínima detectable.

b. Especificidad, a través de la reacción cruzada con FSH.

c. Precisión, mediante las pruebas estadísticas realizadas en cada RIA (Syx, valor F, relación respuesta-error y perfil de imprecisión).

d. Exactitud, por comparación entre el valor observado y el esperado, en diluciones sucesivas de una muestra de concentración conocida.

e. Paralelismo, comparando la pendiente de la curva estándar con la de una realizada con una muestra de suero, aplicando la prueba $t$ de Student.

f. Comparación del antisuero obtenido con el de referencia internacional.

\section{Resultados y discusión}

\section{Extracción y purificación de LH}

El cuadro 1 muestra el contenido y la actividad hormonal de la LH purificada a través de la columna de DEAE-celulosa. EI rendimiento obtenido a partir de la proteína aplicada en la columna fue de $50,5 \%$ que, aunque bajo, logró aumentar la actividad hormonal de la LH (1.136 $\mathrm{UI} / \mathrm{mg}$ en el extracto crudo) en, aproximadamente, 8,5 veces, permitiendo obtener $\mathrm{LH}$ con baja presencia de contaminantes (FSH y TSH) y adecuada para ser empleada como antígeno en la inoculación.

Inmunización en conejos con hLH purificada

El esquema de inmunización seguido permitió la obtención del anti-LH. Al día 23 de la 
Cuadro 1. Purificación de LH mediante DEAE-celulosa

Proteína total recuperada: $4,34 \mathrm{mg}$ Hormona (mg) Actividad hormonal (Ul/mg)

\begin{tabular}{rcc}
\hline LH & 4,23 & 9746 \\
FSH & $8,79 \times 10^{-3}$ & 13,9 \\
TSH & $0,33 \times 10^{-3}$ & $1,15 \times 10^{-5}$ \\
\hline
\end{tabular}

inoculación, se observó una respuesta primaria, indicando la activación del sistema inmune. Con la aplicación de otras dosis de antígeno, se activó la respuesta secundaria (producción de lgG), mejorándose la calidad del antisuero obtenido. La respuesta inmune logró estabilizarse a los 84 días (porcentaje de unión: $49,5 \%$ $\left(C_{1}\right), 47,8 \%\left(C_{2}\right), 47,6 \%\left(C_{3}\right)$, dilución 1:1.000), realizando, posteriormente, punción cardíaca.

\section{Caracterización parcial del antisuero}

Título óptimo. Se realizaron diferentes diluciones de los anti-LH, determinando por RIA el porcentaje de enlace que brinda mayor sensibilidad y obteniéndose una dilución de $1: 1.000$ en los tres antisueros.

Especificidad. Mediante las técnicas de inmunodifusión e inmunoelectroforesis, se pudo observar claramente la formación de una línea de precipitación que indica la existencia de la reacción inmune y, por tanto, la especificidad de los anti- $\mathrm{LH}$. Teniendo en cuenta que el grado de reacción cruzada se expresa como la relación entre la concentración del antígeno específico (LH) necesario para obtener un $50 \%$ de unión y la concentración de la sustancia interferente (FSH) para obtener el mismo porcentaje de unión, se pudo observar que para los tres antisueros el porcentaje de reacción cruzada fue muy bajo $\left(C_{1}: 0,86 \%, C_{2}: 1,3 \%, C_{3}: 0,79 \%\right)$, indicando la alta especificidad de los anti-LH obtenidos, considerando la gran similitud existente entre las gonadotropinas.

Afinidad. Mediante el análisis de regresión lineal de las curvas de Scatchard, los valores obtenidos para la constante de afinidad fueron: $\mathrm{Ka}_{1}: 0,21 \times 10^{10} \mathrm{~L} / \mathrm{mol} ; \mathrm{Ka}_{2}: 0,22 \times 10^{10} \mathrm{~L} / \mathrm{mol} ; \mathrm{Ka}_{3}$ : $0,23 \times 10^{10} \mathrm{~L} / \mathrm{mol}$; valores comprendidos dentro del rango informado en la literatura $\left(10^{9}-10^{12} \mathrm{~L}\right.$ mol)(14), para anticuerpos empleados en inmunoensayos. Estos valores corroboran la especificidad en la reacción entre los epítopes de la hormona y los anticuerpos producidos, proyectando un alto grado de sensibilidad de los inmunoensayos en que se empleen.

Aplicabilidad del anti-LH en RIA y validación del método

Actividad específica de LH marcada: la actividad específica obtenida por el método de sumatoria de pico fue de $36,2 \mu \mathrm{Ci} / \mu \mathrm{g}$ y mediante la curva de desplazamiento del trazador al $50 \%$ de $40,9 \mu \mathrm{Ci} / \mu \mathrm{g}$, valores muy similares, siendo el método de desplazamiento del trazador más exacto ya que involucra la medición en las mismas condiciones en las cuales se va a utilizar el trazador en reacción con el anticuerpo.

Curva estándar: la validación estadística de la curva dosis-respuesta de cada antisuero por regresión lineal y evaluación de la linealidad (coeficientes de correlación: 0,998) estableció su confiabilidad en la cuantificación de la hormona, como puede observarse en el cuadro 3.

Confiabilidad del RIA: el cuadro 2 muestra los resultados globales de los parámetros tenidos en cuenta en el control de calidad del RIA de LH, para uno de los antisueros obtenidos.

El valor promedio del enlace no específico fue de $3,85 \%\left(C_{1}\right), 4,10 \%\left(C_{2}\right)$ y $3,85 \%\left(C_{3}\right)$, valores aceptables ya que se recomiendan inferiores al $5 \%$ de las cuentas totales (14). El porcentaje de unión máxima fue de $25,09 \%\left(C_{1}\right), 23,29 \%\left(C_{2}\right)$ y $25,43 \%\left(\mathrm{C}_{3}\right)$, valores comprendidos dentro del

Cuadro 2. Resultados de control de calidad para RIA de LH.

\begin{tabular}{|c|c|c|c|c|c|c|}
\hline $\begin{array}{l}\text { RIA } \\
\text { PE }\end{array}$ & $\begin{array}{r}\% \text { NSB } \\
<5 \% \mathrm{CT}\end{array}$ & $\begin{array}{c}\text { Bo } \\
20-50 \%\end{array}$ & $\begin{array}{c}b \\
-2,303\end{array}$ & $\begin{array}{r}\text { Syx } \\
<0,23\end{array}$ & \multicolumn{2}{|c|}{$\begin{array}{c}\text { Fobt } \\
\text { Fobt }<\text { Ftab }\end{array}$} \\
\hline \multicolumn{7}{|c|}{ Conejo 3} \\
\hline 1 & 3,47 & 31,03 & $-2,05$ & 0,22 & 1,94 & 3,69 \\
\hline 2 & 4,57 & 22,52 & $-2,13$ & 0,12 & 1,88 & 7,71 \\
\hline 3 & 3,25 & 24,58 & $-2,28$ & 0,21 & 0,56 & 3,20 \\
\hline 4 & 5,00 & 26,77 & $-2,36$ & 0,21 & 1,72 & 5,41 \\
\hline 5 & 5,51 & 23,27 & $-2,15$ & 0,23 & 2,22 & 3,33 \\
\hline 6 & 4,85 & 29,09 & $-2,51$ & 0,23 & 1,44 & 6,94 \\
\hline 7 & 2,42 & 25,48 & $-2,20$ & 0,20 & 0,52 & 6,94 \\
\hline 8 & 1,91 & 25,05 & $-2,34$ & 0,19 & 2,02 & 6,59 \\
\hline 9 & 3,03 & 24,13 & $-2,40$ & 0,22 & 0,61 & 4,46 \\
\hline 10 & 4,54 & 22,26 & $-2,44$ & 0,18 & 2,76 & 4,76 \\
\hline
\end{tabular}

PE: parámetros estadísticos 
Cuadro 3. Comparación de los antisueros obtenidos con un patrón de referencia internacional.

\begin{tabular}{|c|c|c|c|c|c|}
\hline \multirow[t]{2}{*}{$\begin{array}{l}\text { Dosis } \\
\mathrm{ng} / \mathrm{mL}\end{array}$} & \multicolumn{4}{|c|}{ Dilución 1:1000 } & $\begin{array}{r}\text { Dilución } \\
\text { 1:20.000 } \\
\text { Antisuero }\end{array}$ \\
\hline & \multicolumn{2}{|c|}{$\begin{array}{c}C_{1} \\
B / B o\end{array}$} & $\begin{array}{c}C_{2} \\
B / B o\end{array}$ & $\begin{array}{c}C_{3} \\
\text { B/Bo }\end{array}$ & $\begin{array}{c}\text { NIADDK } \\
\text { B/Bo }\end{array}$ \\
\hline 0 & 0 & 00 & 100 & 100 & 100 \\
\hline 5 & 91,6 & & 91,61 & 90,89 & 91,65 \\
\hline 10 & 84,4 & & 85,30 & 82,56 & 84,57 \\
\hline 25 & 71,26 & & 68,99 & 69,92 & 70,47 \\
\hline 50 & 50,3 & & 49,64 & 44,50 & 56,52 \\
\hline 100 & 38,26 & & 37,79 & 35,50 & 36,61 \\
\hline 200 & 23,3 & & 21,29 & 19,25 & 26,00 \\
\hline 320 & 16,0 & & 16,82 & 12,89 & 17,51 \\
\hline \multirow{4}{*}{$\begin{array}{l}\text { Parámetro } \\
\text { RIA Star }\end{array}$} & \multicolumn{2}{|c|}{ os $F \quad 0,39 \mathrm{Ob}$} & bt 0,75 Obt & 2,0 & $t \quad 0$, \\
\hline & \multicolumn{2}{|c|}{$5,41 \mathrm{Tab}$} & 4,35 Tab & 6,59 Tab & 5,41 Tab \\
\hline & $b$ & $-2,23$ & $-2,27$ & $-2,34$ & $-2,20$ \\
\hline & Syx & 0,19 & 0 & 0,19 & 0,22 \\
\hline
\end{tabular}

rango de 20 a $50 \%$ que garantiza el desplazamiento posterior por el analito para las diferentes hormonas (7).

Los valores de la pendiente siempre se encontraron cercanos al valor teórico $(-2,303)$ y dentro de los límites de confianza del 95\% (-2,63<$2,303<-1,97$ ), asegurando que se llega al estado de equilibrio en la reacción antígeno-anticuerpo.

Los valores Syx obtenidos estuvieron por debajo del valor límite $(0,23)(7)$ indicando un buen índice de precisión para la curva dosisrespuesta. El valor $\mathrm{F}$ obtenido fue inferior al tabulado al $95 \%$, indicando que la línea de regresión lineal que representa la curva dosisrespuesta es lineal.

El perfil de precisión mostró un rango óptimo entre 25 y $320 \mathrm{ng} / \mathrm{mL}$ puesto que su porcentaje de variación se encuentra dentro de los límites permitidos menores del $10 \%$ (15), siendo la mínima dosis detectable de 2,23 $\left(C_{1}\right), 1,16\left(C_{2}\right)$ y $1,18 \mathrm{ng} / \mathrm{ml}\left(\mathrm{C}_{3}\right)$, lo que demuestra una buena sensibilidad, permitiendo el análisis de suero humano en el RIA, con la certeza de ser posible su medición.

En las cartas de control de calidad en el intraanálisis pudo apreciarse que las muestras testigo (control bajo, medio y alto) se encuentran bajo control estadístico, lo cual evidencia la confiabilidad del método cuando se empleen los antisueros obtenidos.

Mediante la prueba de paralelismo, se pudo confirmar que el antisuero es capaz de distinguir entre la muestra y el trazador, compitiendo por el anticuerpo y existiendo el desplazamiento para obtener las curvas dosis-respuesta paralelas. Al comparar los datos de la curva dosis-respuesta de los antisueros con la obtenida utilizando un patrón de referencia internacional (anti-LH conejo NIADDK), se pudo observar una gran similitud en la capacidad de unión de los antisueros (cuadro 3).

A pesar de la diferencia notable en el título (1:1000 contra $1: 20.000)$, los antisueros obtenidos en este trabajo, también, se comportan de manera específica y permiten desarrollar un análisis de alta sensibilidad.

Si se comparan las constantes de afinidad $\left(0,2 \times 10^{10} \mathrm{~L} / \mathrm{mol}\right.$ con NIADDK $\left.0,95 \times 10^{10} \mathrm{~L} / \mathrm{mol}\right)$ puede verse que los valores son muy similares, lo cual corrobora aun más la validez de los antisueros obtenidos como primer anticuerpo de alta especificidad en el RIA.

En conclusión, los antisueros obtenidos en este trabajo presentan características de confiabilidad que permiten emplearlos en la cuantificación de LH en RIA, ajustándose a los requerimientos de linealidad lo que permite ratificar su utilidad en los análisis de diagnóstico y en la investigación.

\section{Agradecimientos}

Los autores expresan su agradecimiento al Programa IPICS, Universidad de Uppsala, Suecia; a Colciencias y al Departamento de Química de la Universidad Nacional de Colombia.

\section{Referencias}

1. Zhang FP, Markkula M, Toppari J, Huhtaniemi ! Novel expression of luteinizing hormone subunit genes in the rat testis. Endocrinol 1995;136:2904-12.

2. Veldhuis J, Urban R, Dufau M. Differential responses of biologically active luteinizing hormone secretion in older vs. young men to interruption of androgen negative feedback. J Clin Endocrinol Metab 1994; 79:993-69. 
3. Uiloa A, Midgley A, Padmanabhan V, Beitins I. Follicle stimulating isohormones: characterization and physiological relevance. End Rev 1995;16:765-87.

4. Goodman L, Gilmar A. Las bases farmacológicas de la terapeútica. $8^{\text {a }}$ ed. México: Panamericana; 1991.

5. Farinati Z, Galanternik A, Malkischer S. Normalización y control de calidad del radioinmunoanálisis; 1980.

6. Lowry O, Rosebrough N, Farr L, Randall, R. Protein measurement with the folin phenol reagent. J Biol Chem 1951;193:265-75.

7. Jeffcoate S, Garza J, Sánchez V. Preparation of book reagents for the radioimmunoassay of thyroid hormones. Santiago de Chile: IDEA; 1984.

8. Clausen J. Técnicas inmunoquímicas para la identificación y estimación de macromoléculas. México: Manual Moderno; 1975.

9. Roitt 1, Brostoff J, Male D. Inmunología. $2^{\text {a }}$ ed. Santiago de Chile: Salvat; 1991.
10. Rodbard D. Statistical quality control and routine data processing of radioinmmunoassay and immunoradiometric assays. Clin Chem 1974;20:1255-9.

11. Greenwood F, Hunter W. Preparation of iodine-131 labelled human growth hormone of high specific activity. Nature 1962;194:465-9.

12. Rincón JR, Suárez A. Determinación de los niveles séricos de hGH en niños bogotanos preadolescentes normales (tesis). Santa $\mathrm{Fe}$ de Bogotá: Universidad Nacional de Colombia; 1992.

13. Camero G, Esquivel DF. Ensayos de obtención y purificación de LH a partir de hipófisis humanas congeladas (tesis). Santa Fe de Bogotá: Universidad Nacional de Colombia; 1991.

14. Chard T. Introduction to radioimmunoassay and related techniques. 4th ed. Amsterdam: Elsevier; 1990.

15. Ekins RP. The precision profile: its use in assay design assessment and quality control. Edimburg: Churchill Livingstone; 1980. 